\title{
Misoprostol: a solução não é tão simples
}

\section{Misoprostol: the solution is not so easy}

Helena Lutéscia L. Coêlho

Coodenadora do Grupo de Prevenção ao Uso Indevido de Medicamentos da Universidade Federal do Ceará 


\section{Misoprostol: a solução não é tão simples}

\section{Misoprostol: the solution is not so easy}

A publicação recente no Lancet $^{6}$, de um artigo no qual são apresentados 41 casos de crianças nascidas com Síndrome de Moebius (quadro de anomalias congênitas associadas à malformação de nervos cranianos), tendo sido expostas ao misoprostol (Citotec ${ }^{\circledR}$, Biolab-Searle) durante o primeiro trimestre da gestação, reabre o debate em torno da presença dessa droga no mercado brasileiro, por não se ver no horizonte a perspectiva da legalização do aborto no Brasil. A impossibilidade, para a grande maioria das mulheres brasileiras, de consumar o abortamento de modo seguro e acessível, após a falha da tentativa com o misoprostol, trás consigo o risco do nascimento de crianças com deformidades extensas e muitas vezes incapacitantes (hidrocefalia, deformidades ou ausência de mãos e pés, atrofia cerebral, entre outras).

Um estudo caso-controle, também realizado em nosso País ${ }^{8}$, no qual se comparava neonatos com Síndrome de Möebius (94 casos) com neonatos que apresentavam um outro tipo de malformação conhecido como spina bífida (controles), evidenciou que os casos tinham uma chance 25,7 vezes maior do que os controles, de terem sido expostos ao misoprostol.

Todavia, não se conseguiu demonstrar freqüência anormal de malformações em um estudo de coorte ${ }^{7}$, em que as gestações de 86 mulheres que haviam utilizado misoprostol no primeiro trimestre e não abortaram, foram acompanhadas até o desfecho. Já que malformação é um evento raro, é mais difícil estudar a sua freqüência pelo método da coorte, porém, daria uma resposta mais definitiva à questão.

Os resultados de alguns estudos experimentais, realizados em animais de laboratório, têm reproduzido os achados em humanos, o que reforça a hipótese da ação teratogênica do misoprostol ${ }^{1,2,7}$.

\section{Antecedentes}

Os primeiros trabalhos evidenciando o uso indiscriminado do misoprostol, como abortivo no Brasil, foram realizados pelo Grupo de Prevenção ao Uso Indevido de Medicamentos da Universidade Federal do Ceará (GPUIM), em 1990-942-5. Foi também no Ceará que se detectaram os primeiros casos de malformação em bebês expostos ao misoprostol in utero ${ }^{5}$. O fármaco é hoje classificado pela FDA entre as drogas teratogênicas, e este efeito adverso é citado em todas as fontes bibliográficas importantes da área de medicamentos. Indicado para prevenção e tratamento de úlcera gástrica, o Cytotec teve suas vendas suspensas no Ceará, por decisão judicial, em julho de 1992 e submetidas ao controle da Portaria 27, em todo o território nacional, no mesmo mês; em alguns Estados foram tomadas medidas diferenciadas para o controle da comercialização do produto.

As vendas do Cytotec' no País caíram em cerca de $80 \%$ logo após essas determinações ${ }^{3}$, mas a comercialização clandestina ou irregular do medicamento propiciou um novo crescimento na freqüência de curetagens.

\section{O Misoprostol é um Medicamento Eficaz como Anti-úlcera?}

Uma revisão cuidadosa dos estudos sobre a eficácia do misoprostol para tratamento de úlcera gástrica, mostra-nos que a única justificativa segura para a sua indicação em lugar de outros medicamentos é a prevenção da erosão gástrica em pacientes de risco tratados com anti-inflamatórios não esteróides, particularmente em idosos. Por este motivo, é comum a prescrição do misoprostol por reumatologistas. 


\section{A U tilidade do Misoprostol em 0 bstetrícia}

O misoprostol é um análogo sintético da prostaglandina $E$ e, como tal, aumenta o tônus uterino, favorece o desenvolvimento de contrações, além de causar o amolecimento do colo do útero, facilitando a dilatação necessária à realização de curetagem, bem como de outros procedimentos obstétricos. Os fatos acontecidos no Brasil chamaram a atenção para a utilidade do medicamento em obstetrícia, superior a de outras prostaglandinas, por sua eficácia, facilidade de uso e baixo custo. No mercado farmacêutico brasileiro não há um outro medicamento igualmente útil, seguro e eficaz para essa indicação. A situação é muito complexa, já que esse uso não foi autorizado pelo governo brasileiro e nem sequer pelo laboratório produtor do medicamento, o qual permanece na cômoda situação de auferir os lucros sem pagar o ônus de responsabilizar-se pelo emprego do misoprostol em obstetrícia.

\section{Misoprostol e Aborto Legal}

Ensaios clínicos realizados em países onde o aborto é legalizado mostraram que, quando utilizado sob cuidadosa atenção médica (exame prévio da paciente, contra-indicações e aconselhamento, introdução dos comprimidos na vagina de modo apropriado, acompanhamento dos resultados, repetição do uso quando necessário) o misoprostol pode ter a sua eficácia abortiva otimizada. Mesmo nessas situações, a percentagem de falhas pode ultrapassar os $10 \%$, o que exigiria o emprego de outro método para o esvaziamento uterino, dado que houve exposição do concepto ao medicamento. Os cuidados médicos também dizem respeito à possibilidade de

\section{REFERÊNCIAS}

1. COELHO, H.L.L. O que está em jogo no caso Cytotec. Ciênc. Hoje, 13: 60-2, 1991.

2. COELHO, H.L.L. et al. Selling abortifacients over the counter in pharmacies in Fortaleza, Brazil. Lancet, 338: 247, 1991.

3. COELHO, H.L.L. et al. Misoprostol and illegal abortion in Fortaleza, Brazil. Lancet, 341: 1261-3, 1993.

4. COELHO, H.L.L. et al. Misoprostol: the experience of women in Fortaleza, Brazil. Contraception, 49: 101-9, 1994. ocorrer intolerância, hemorragia, permanência de restos ovulares, infecção e outras complicações.

\section{A Situação Atual}

A constatação, pela Vigilância Sanitária do Estado de São Paulo, de irregularidades existentes na distribuição do Cytotec $^{\circledR}$, mostra-nos a impossibilidade do controle da situação, sem o envolvimento responsável da Biolab-Searle, indústria que produz o medicamento no Brasil. Neste aspecto, vale salientar que, a entrada do Cytotec no País por vias ilegais sugere que o controle último deveria partir da matriz do laboratório e as suas subsidiárias. Caso isso não aconteça, o governo brasileiro e a companhia Searle poderão ser responsabilizados legalmente pelo nascimento de centenas, ou talvez de milhares de crianças malformadas que foram expostas ao misoprostol no útero materno, desde que já exista base científica para fundamentar os processos.

Assim, procuramos demonstrar a complexidade do problema e sugerir que não sejam buscadas soluções simplistas. A retirada do medicamento do mercado, só irá contribuir para mascarar a realidade e penalizar mais ainda a saúde das mulheres brasileiras, principalmente das mulheres pobres, que são a grande maioria.

Helena Lutéscia L. Coêlho Coodenadora do Grupo de Prevenção ao Uso Indevido de Medicamentos da Universidade Federal do Ceará
5. FONSECA,W.V.C. et al. Misoprostol and congenital malformations. Lancet, 337: 762-3, 1991.

6. GONZALEZ,C.H.et al. Congenital abnormalities in forty Brazilian children associated with misoprostol use in the first semester of pregnancy. Lancet, 351: 1624-7, 1998.

7. PASTUSZAK, A.L. et al. Misoprostol use during pregnancy is associated with an increased risk of Möebius sequence. Teratology, 55:36, 1997.

8. SCHÜLLER, L. et al. Pregnancy outcome after abortion attempt with misoprostol. Teratology, 55: 36, 1997. 